To the Editors

\title{
A poem and drawings by a 14 year old child with Anorexia nervosa
}

Sri Lanka Journal of Child Health, 2014; 43: 185

(Key words: Child; poem; drawings; Anorexia nervosa)

A very unique poem has been written by a 14 year old girl I treated for Anorexia nervosa, describing her experience of the illness. It is accompanied with a drawing, which is also the creation of this very talented young girl. She has given me permission to reproduce these in a Scientific Journal.

\section{Skinny bones}

I wanted to experience

But it led to an addiction.

3 full meals a day,

To nothing at all...

I looked in the mirror

To see nothing but fat.

I saw pictures of models

And thought I want to be exactly like that.

I wanted to eat less,

But ate nothing instead.

"Don't eat, don't eat"

This little voice said.

I was afraid of food

Afraid of gaining weight.

If I didn't find help

It might have been too late.

Thoughts of suicide

Running through my head.

"Why am I here?"

I wanted to be dead.

I danced a blade across my wrist.

I watched as the blood had now started to drip.

I knew I'm suffering in nothing but pain,

I knew it all, but my tears would still slip.

I didn't talk with anyone.

I pushed people away.

I cried my self to sleep.

I cried night and day.

My bones started to show.

I had constipation.

My hair started to fall.

It was nothing but frustration.

Others saw skin and bones

But fat was all I see.

They told me I was too thin,

Why can't they let me be?

Fainting when I stand

I was now too weak.

Afraid to ask help,

I just couldn't speak.

The next thing you know

I'm on a hospital bed.

So many needles in my arm.

I just couldn't be fed.

My father worried a lot,

My grandma would even cry

I felt sorry for them both

As their only daughter might die.

I finally got help.

I stopped my addiction

Anorexia ruined my life.

I was no longer in affliction.

\section{By: Shenuri Fernando}



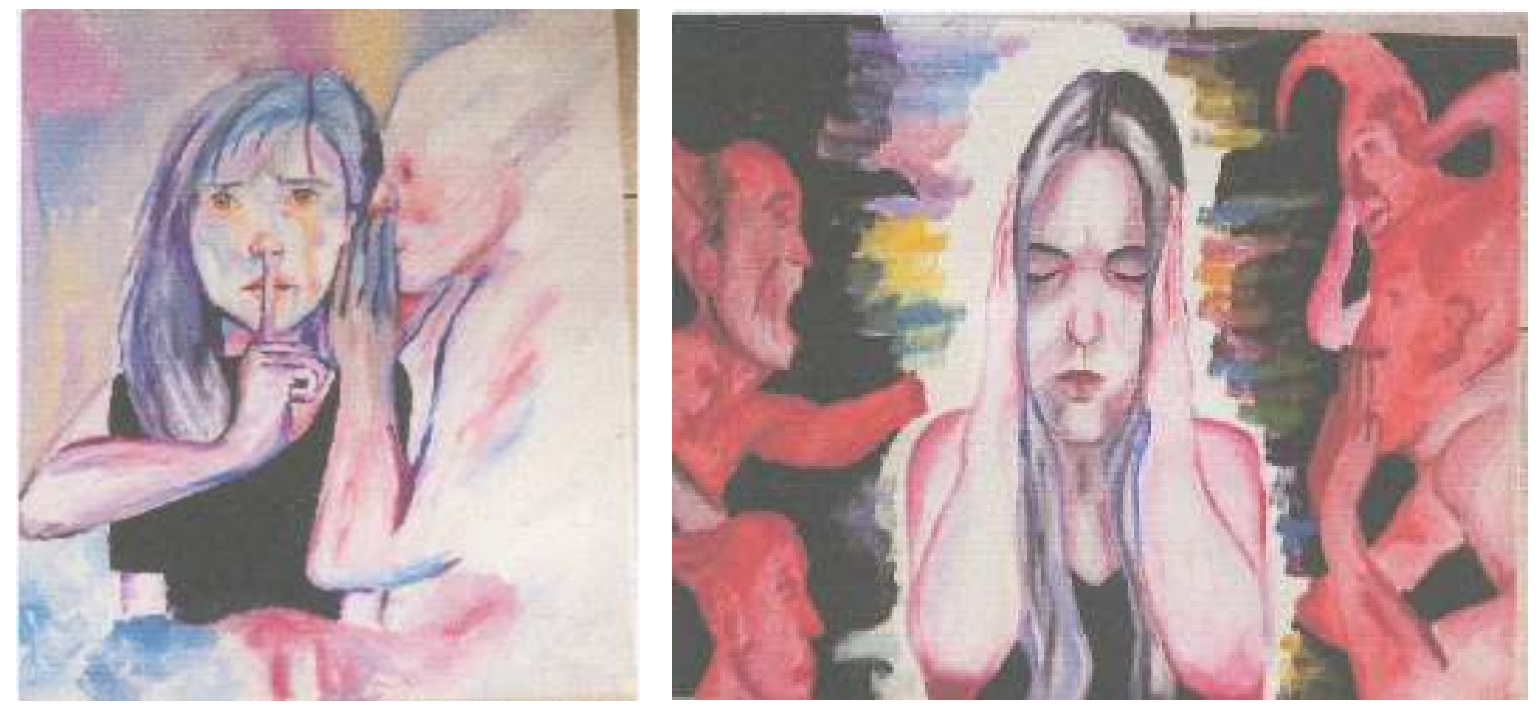

Professor Hemamali Perera

Department of Psychological Medicine

University of Colombo

Faculty of Medicine

Kinsey Road, Colombo 08

Sri Lanka 